Article

\title{
Synergy between Low Earth Orbit (LEO)-MODIS and Geostationary Earth Orbit (GEO)_GOES Sensors for Sargassum Monitoring in the Atlantic Ocean
}

\author{
Audrey Minghelli 1,2,*(D), Cristele Chevalier ${ }^{3,4}$, Jacques Descloitres ${ }^{5}$, Léo Berline ${ }^{3,4}$ (D), Philippe Blanc 6 \\ and Malik Chami ${ }^{7}$ (D)
}

1 Laboratoire d'Informatique et Système (LIS), Université de Toulon, CNRS UMR 7020, F-83041 Toulon, France

2 Laboratoire d'Informatique et Système (LIS), Aix Marseille Université, F-13288 Marseille, France

3 Mediterranean Institute of Oceanography (MIO), Aix Marseille Université, CNRS, IRD, UM 110,

F-13288 Marseille, France; cristele.chevalier@mio.osupytheas.fr (C.C.); leo.berline@mio.osupytheas.fr (L.B.)

4 Mediterranean Institute of Oceanography (MIO), Université de Toulon, F-83041 Toulon, France

5 AERIS/ICARE Data and Services Center, University of Lille, CNRS, CNES, UMS 2877, F-59000 Lille, France; jacques.descloitres@univ-lille.fr

6 Observation, Impacts, Energy (OIE), MINES ParisTech, PSL University, F-06904 Sophia Antipolis, France; philippe.blanc@ensmp.fr

7 Laboratoire Atmosphères Milieux Observations Spatiales (LATMOS), Sorbonne Université, CNRS-INSU, F-06304 Nice, France; malik.chami@upmc.fr

* Correspondence: minghelli@univ-tln.fr

Citation: Minghelli, A.; Chevalier, C.; Descloitres, J.; Berline, L.; Blanc, P.; Chami, M. Synergy between Low Earth Orbit (LEO)—MODIS and Geostationary Earth Orbit (GEO)_GOES Sensors for Sargassum Monitoring in the Atlantic Ocean. Remote Sens. 2021, 13, 1444.

https://doi.org/10.3390/rs13081444

Academic Editor: Deepak R. Mishra

Received: 19 February 2021

Accepted: 5 April 2021

Published: 8 April 2021

Publisher's Note: MDPI stays neutral with regard to jurisdictional claims in published maps and institutional affiliations.

Copyright: (c) 2021 by the authors. Licensee MDPI, Basel, Switzerland. This article is an open access article distributed under the terms and conditions of the Creative Commons Attribution (CC BY) license (https:// creativecommons.org/licenses/by/ $4.0 /)$.
Abstract: Since 2011, massive stranding of the brown algae Sargassum has regularly affected the coastal waters of the West Caribbean, Brazil, and West Africa, leading to heavy environmental and socio-economic impacts. Ocean color remote sensing observations as performed by sun-synchronous satellite sensors such as MODIS (NASA), MERIS (ESA), or OLCI (ESA/Copernicus) are used to provide quantitative assessments of Sargassum coverage through the calculation of indices as the Alternative Floating Algae Index (AFAI). Sun-synchronous sensors usually provide at best one daytime observation per day of a given oceanic area. However, such a daily temporal revisit rate is not fully satisfactory to monitor the dynamics of Sargassum aggregation due to their potentially significant drift over the course of the day as a result of oceanic currents and sea surface wind stress. In addition, the sun glint and the presence of clouds limit the use of low earth orbit observations, especially in tropical zones. The high frequency sampling provided by geostationary sensors can be a relevant alternative approach in synergy with ocean color sun-synchronous sensors to increase the temporal resolution of the observations, thus allowing efficient monitoring of Sargassum dynamics. In this study, data acquired by a geostationary satellite sensor located at 36,000 km from Earth, namely GOES-16 (NASA/NOAA), which was primarily designed for meteorology applications, are analyzed to investigate the Sargassum dynamics. The results demonstrate that a GOES-16 hourly composite product is appropriate to identify Sargassum aggregations using an index commonly used for vegetation monitoring, namely NDVI (Normalized Difference Vegetation Index). It is also shown that GOES hourly observations can significantly improve the simulated drift obtained with a transport circulation model, which uses geostrophic current, wind, and waves. This study thus highlights the significant relevance of the effective synergy between sun-synchronous and geostationary satellite sensors for characterizing the Sargassum dynamics. Such a synergy could be summarized as follows: (i) A sun-synchronous sensor enables accurate Sargassum detection and quantitative estimates (e.g., fractional coverage) through AFAI Level-2 products while (ii) a geostationary sensor enables the determination of the displacement features of Sargassum aggregations (velocity, direction).

Keywords: ocean color; sargassum; AFAI index; geostationary remote sensing; GOES 


\section{Introduction}

Unprecedented massive stranding of the brown macro-algae Sargassum fluitans and S. natans (hereinafter Sargassum) has been observed along the coastline of French Guyana, the Antilles Islands, and the Caribbean Sea over the last decade. These pelagic algae float in the upper surface layer in offshore waters and can cluster into large aggregations that are transported by currents over long distances across the Atlantic Ocean. Thus, satellite data are highly convenient to determine the algae spatial distribution. A spectral index called Maximum Chlorophyll Index (MCI) was first defined by Gower et al. [1] for the Medium Resolution Imaging Spectrometer (MERIS) satellite sensor (300 m resolution). Such an index relies on the spectral peak of the water leaving radiance at $709 \mathrm{~nm}$ that is mostly induced by the Sargassum algae optical signature. It was shown that such a peak indicates the occurrence of a high surface concentration of chlorophyll $a$, and allows extensive areas of pelagic vegetation to be detected $[1,2]$. The MCI index was previously used to study the spatial distribution of Sargassum in the Gulf of Mexico and in the western Atlantic waters [3,4]. The Sentinel-3/OLCI (Ocean and Land Color Instrument) sensor was launched in 2016 to ensure the continuity of MERIS observations. OLCI was thus designed to provide spatial resolution and spectral bands similar to MERIS [5].

$\mathrm{Hu}[6]$ proposed a Floating Algae Index (FAI) to analyze the data acquired by the Moderate Resolution Imaging Spectroradiometer (MODIS) with the objective of detecting and tracing blooms of Ulva prolifera macroalgae species in the Yellow Sea near Qingdao, China $[7,8]$. Since $F A I$ was proposed based on the vegetation red-edge reflectance observed between 675 and $750 \mathrm{~nm}$, such an index could be relevant to detect any floating vegetation including Sargassum [9]. However, both Sargassum slicks and clouds show high FAI values. Considering the difficulty of performing a robust cloud masking, Wang and $\mathrm{Hu}$ [10] suggested the Alternative Floating Algae Index (AFAI), which better separates Sargassum from clouds, using data measured in alternative spectral bands, namely $667 \mathrm{~nm}, 748 \mathrm{~nm}$, and $869 \mathrm{~nm}$.

High spatial resolution sensors which typically have a resolution of between $10 \mathrm{~m}$ and $60 \mathrm{~m}$ such as Sentinel-2/MSI (MultiSpectral Instrument) are also relevant to detect Sargassum. Ody et al. [11] recently adapted the AFAI index to MSI spectral features using the bands at $665 \mathrm{~nm}, 833 \mathrm{~nm}$, and $940 \mathrm{~nm}$, thus providing the so-called Modified Floating Algae Index (MFAI).

In addition to Sargassum detection, some algae indices allow the Sargassum fractional cover within the pixels to be quantified and converted into biomass per unit area. Wang and $\mathrm{Hu}$ [10] proposed a linear relationship between the AFAI and the fraction of pixels covered by Sargassum. To estimate the AFAI value for a pixel covered by $100 \%$ of Sargassum, they used bucket measurements and radiative transfer simulations. Wang et al. [12] extended this approach to estimate biomass using field measurements.

Ocean color sun-synchronous sensors are then able to provide indices that can be linked to quantitative parameters such as fractional coverage and biomass of Sargassum. However, these sensors provide at best daily retrievals and sometimes fewer in very cloudy conditions, as it frequently happens over most of the Tropical Atlantic Ocean. Thus, the temporal variation of Sargassum and hence their dynamics remain difficult to evaluate. Yet, Sargassum are known to drift rapidly (as much as $17 \mathrm{~km}$ over the course of one day) due to ocean currents and sea surface wind stress [11]. Geostationary satellite observations could be relevant to monitor Sargassum thanks to their high temporal revisit rate, typically every 15 to $30 \mathrm{~min}$. The analysis of data acquired by the Korean geostationary sensor GOCI together with Lagrangian particle modeling demonstrated the feasibility of tracing the trajectories of pelagic Sargassum aggregation using this type of satellite orbit [13]. GOCI radiometric sensitivity is specifically dedicated to measuring low level signals such as those encountered in oceanic waters. Unfortunately, the GOCI orbit is not designed to observe the Atlantic Ocean. Therefore, there is currently a lack of geostationary sensors designed for ocean color applications to observe areas in the Atlantic Ocean where Sargassum strongly proliferate [13]. 
GOES-16 ABI is a geostationary sensor that provides data over the Atlantic Ocean. Although it is not designed for observing ocean targets, it may be possible to use it to monitor Sargassum patterns. GOES provides only 3 spectral bands in the visible to nearinfrared domain, i.e., blue, red, and Near Infra-Red (NIR) with a revisit rate of $15 \mathrm{~min}$ (32 images per day). GOES spatial resolutions are $1 \mathrm{~km}, 500 \mathrm{~m}$, and $1 \mathrm{~km}$ for the blue, red, and NIR wavelengths respectively. Thus, the AFAI cannot be calculated using GOES data because the required bands are missing. However, the well-known NDVI index [14,15], which is commonly used to monitor land vegetation, can be calculated.

In this study, the objective is to demonstrate the feasibility of quantifying the temporal variation of Sargassum from high-temporally resolved data acquired by a geostationary sensor designed for weather forecast applications, namely GOES-16 ABI. GOES is used in synergy with the MODIS sun-synchronous sensor to characterize Sargassum dynamics.

The paper is organized as follows: The study area, namely the eastern part of Saint Lucia Island in the western area of the North Atlantic Ocean, is first described (Section 2). The main features of the satellite data and the proposed methodology using GOES data in synergy with MODIS observations are then outlined (Section 2). The spatial variation of MODIS AFAI Level-2 products and the time variation of NDVI product derived from GOES are presented in Section 3. Ways in which the quality of GOES raw data could be improved to enhance its potential to observe Sargassum are discussed in Section 4. Finally, the analysis of GOES data for improving the forecast of Sargassum transport and stranding is performed by comparing it with estimated drift velocity from an ocean circulation model (Section 4).

\section{Data and Methods}

\subsection{Study Area}

The study area is located in the Caribbean Sea in the North Atlantic Ocean. The frequent influx of Sargassum that reached the French Antilles in the past, especially between 2015 and 2018, represents a major threat to the ecology, health, and economy of these islands [16]. These islands can each receive an average value of $150,000 \mathrm{~m}^{3}$ of seaweed during major stranding episodes [17]. All the bays located on the east coasts are affected by the Sargassum stranding. The west coasts can also be affected by Sargassum presence due to ocean currents. Our specific study area is located west of Martinique and Saint Lucia Islands $\left(13-17^{\circ} \mathrm{N}\right.$ and $60-63^{\circ} \mathrm{W}$, white box in Figure 1$)$. The selected temporal period for the data analysis is the month of August 2018, which corresponds to a time where Sargassum was abundant as revealed by MODIS data [11,18].
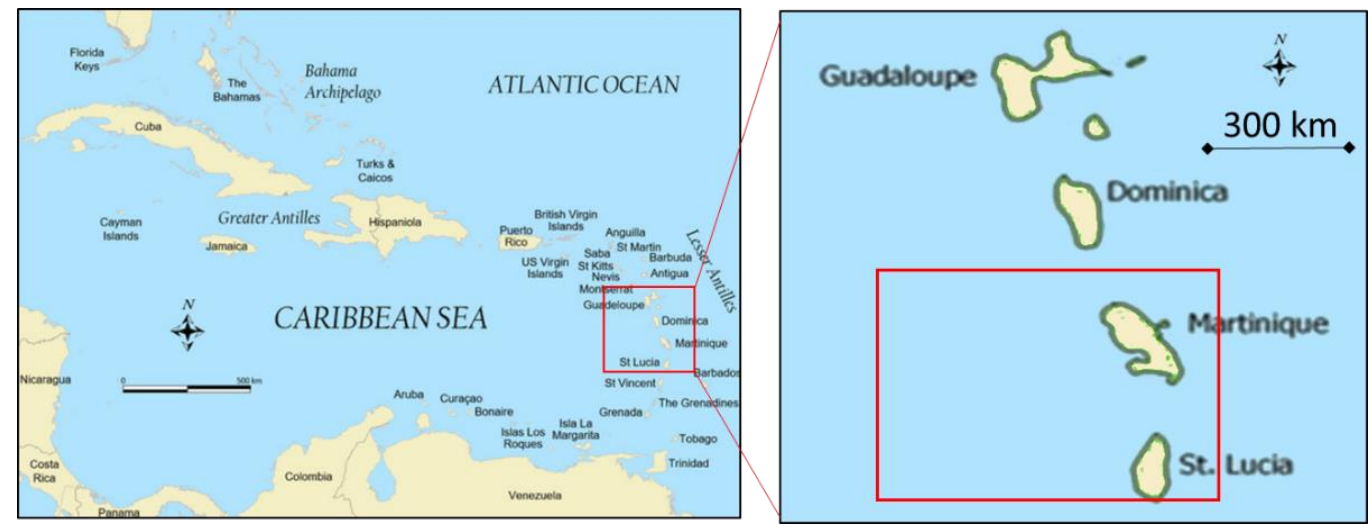

Figure 1. Study area (white box): The Antilles archipelago in the North Atlantic Ocean $\left(13-17^{\circ} \mathrm{N}\right.$ and $\left.60-63^{\circ} \mathrm{W}\right)$. 


\subsection{Satellite Data}

MODIS is a satellite sensor launched by NASA [19] in 1999, on board the Terra satellite and in 2002, on board the Aqua satellite. MODIS allows the entire Earth to be observed every 1 to 2 days. MODIS acquires data in 36 spectral bands ranging from $0.4 \mu \mathrm{m}$ to $14.4 \mu \mathrm{m}$. Observations are performed at various spatial resolutions ( 2 bands at $250 \mathrm{~m}, 5$ bands at $500 \mathrm{~m}$, and 29 bands at $1 \mathrm{~km}$ ). In this study, the bands at $667 \mathrm{~nm}, 748 \mathrm{~nm}$, and $869 \mathrm{~nm}$ at a 1-km resolution of the Terra satellite are exploited to calculate AFAI. A composite RGB image acquired on 8 August 2018 14:35 UTC is shown in Figure 2a. That image covers the Islands from the North to the South: Montserrat, Guadeloupe, Dominica, Martinique, and Saint Lucia.

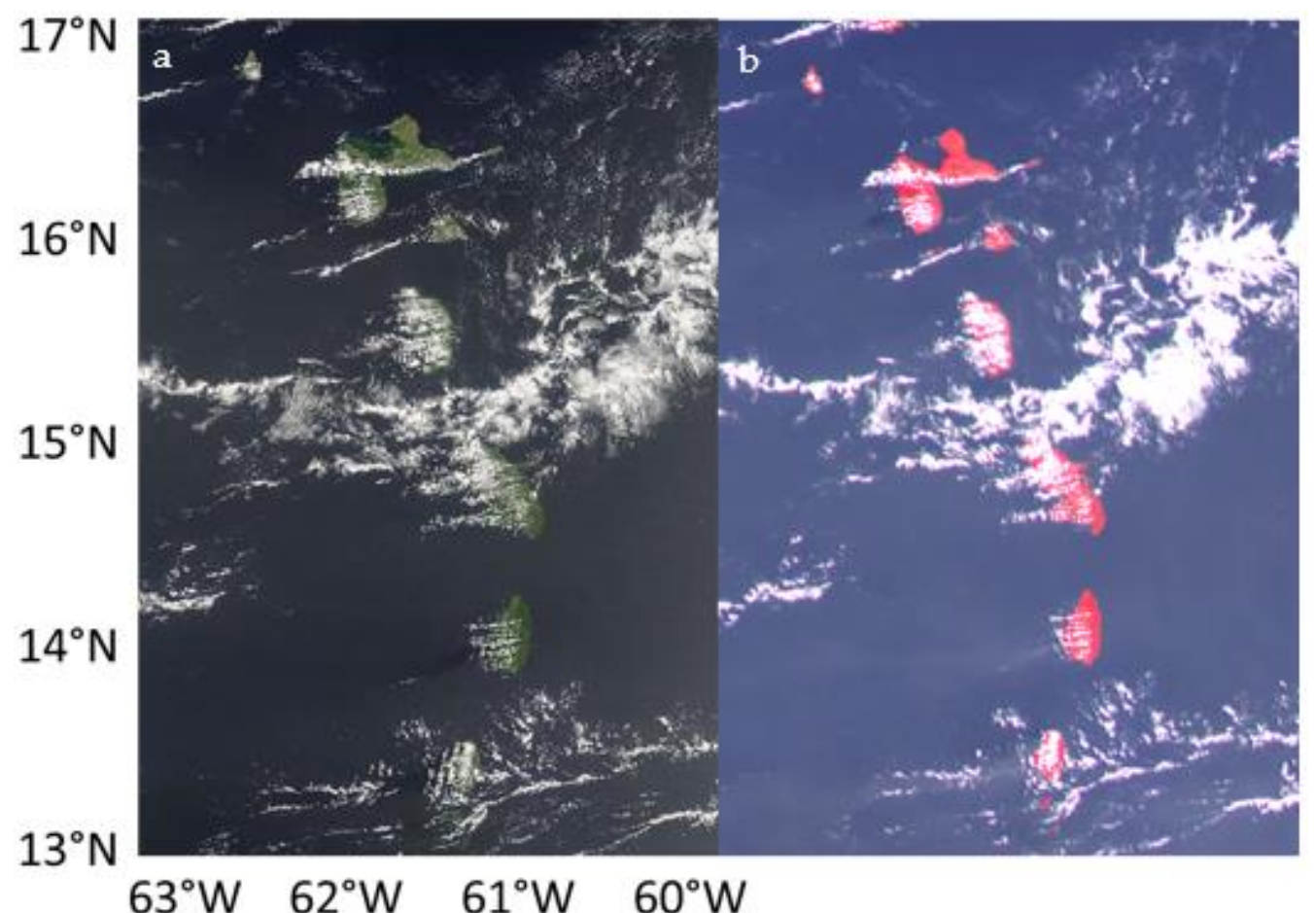

Figure 2. (a) Example of color composite from Moderate Resolution Imaging Spectroradiometer (MODIS) (RGB) (left panel) and (b) GOES (Near Infra-Red (NIR)-G-B) (right panel) acquired on 8 August 2018 at 14:35 and 14:30 UTC respectively i.e., ca. 10:30 local solar time.

The Advanced Baseline Imager (ABI) is the primary instrument on the GOES-R Series for imaging Earth's weather, oceans, and environment. GOES-ABI is a multi-channel passive imaging radiometer designed to observe the western hemisphere and provides relevant information for the analysis of land surfaces, atmosphere, and cloud cover. GOES-ABI observes the Earth in 16 large spectral bands ranging from $0.47 \mu \mathrm{m}$ to $13.3 \mu \mathrm{m}$, including two channels in the visible spectrum, four channels in the near-infrared range, and 10 channels in the infrared range. GOES-ABI improves by a factor of 3,4 , and 5 the spectral, spatial, and temporal resolutions provided by the previous generation of GOES sensors, respectively. ABI concurrently produces a full disk every $15 \mathrm{~min}$. In the visible domain, ABI's spatial resolution is $1 \mathrm{~km}$ for the blue band $(470 \mathrm{~nm})$ and the NIR $(860 \mathrm{~nm})$ band and $500 \mathrm{~m}$ for the red band $(640 \mathrm{~nm}$ ). The Signal-to-Noise Ratio (SNR) is around 1200, 500, and 800 for the blue, red, and NIR bands, respectively, which is quite high compared to other meteorological sensors [20,21]. A false-color NIR-G-B composite acquired on 8 August 2018 at 14:30 UTC is shown in Figure 2b. That image covers the same area as MODIS at almost the same time. Clouds are located at the same place in both images. 


\subsection{Environmental Data}

The Sargassum aggregation dynamic is linked to environmental data such as ocean current and temperature. The ocean current velocity and direction are obtained from OSCAR provided by NASA. The "Third Degree Sea Surface Velocity" product is a five-day temporal composite. Such a product is a direct computation of global surface currents using satellite sea surface height, $10 \mathrm{~m}$ wind, and surface temperature [22]. Currents are calculated using a quasi-steady geostrophic model together with an eddy viscosity-based wind-driven geostrophic component and a thermal wind adjustment.

The Sargassum motion derived from GOES observations was further compared to the motion expected from operational oceanographic modeled products. As described in Jouanno et al. [23] the modeled surface drift velocity was calculated by adding (i) surface velocity from the ocean circulation model (here the "Operational Mercator global ocean analysis and forecast system at 1/12 degree" (https://marine.copernicus.eu/ [24], accessed on 5 April 2021)), (ii) the Stokes velocity (https:/ / marine.copernicus.eu/ [24], accessed on 5 April 2021), and (iii) 1\% of surface wind velocity (http:/ /cersat.ifremer.fr/, https:/ /marine.copernicus.eu/ [24], accessed on 5 April 2021). Temperature data were provided by GHRSST (Group for High Resolution Sea Surface Temperature), which is a merged multi-sensor Level-4 SST analysis product elaborated by Jet Propulsion Laboratory (http:/ / podaac.jpl.nasa.gov/Multi-scale_Ultra-high_Resolution_MUR-SST, accessed on 5 April 2021).

\subsection{Methodology}

MODIS Level-1B data (i.e., Top-of-the-Atmosphere (TOA) radiance) were provided by NASA (ladsweb.modaps.eosdis.nasa.gov, accessed on 5 April 2021). They were used to compute the AFAI following Wang and Hu's approach [10] (Equation (1)):

$$
\mathrm{AFAI}=\mathrm{R}\left(\lambda_{2}\right)-\mathrm{R}\left(\lambda_{1}\right)-\left[\mathrm{R}\left(\lambda_{3}\right)-\mathrm{R}\left(\lambda_{2}\right)\right] \times \frac{\lambda_{2}-\lambda_{1}}{\lambda_{3}-\lambda_{1}}
$$

where $\lambda_{1}=667 \mathrm{~nm}, \lambda_{2}=748 \mathrm{~nm}$, and $\lambda_{3}=869 \mathrm{~nm}$, which correspond to MODIS bands 13, 15 , and 16. $R(\lambda)$ is the corrected reflectance derived from MODIS observations. The TOA radiance was corrected for molecular (Rayleigh) scattering and gaseous absorption using NASA's Ocean Color Science Software (OCSSW-SeaDAS) package. The correction for the aerosol effects was not performed in this study to make sure that THE Sargassum optical signature WAs not removed from the data analysis. This is because the water reflectance is not necessarily close to zero in the NIR band when Sargassum are present, thus preventing the application of the black pixel atmospheric correction method commonly used to derive aerosol properties over open ocean waters [25]. Clouds were flagged using the OCSSW mask based on a threshold technique using a value of 0.030 at $2130 \mathrm{~nm}$. Additional masking for clouds, sun glint, and cloud shadows was applied following Wang and $\mathrm{Hu}$ [10].

While the AFAI is very sensitive to Sargassum optical signature when using MODIS data, it is also sensitive to the water spectral reflectance, to potential residual sun glint contamination, and to the presence of aerosols. Thus, the presence of Sargassum cannot just be determined using a constant threshold value of AFAI. Therefore, the deviation of AFAI with respect to the residual AFAI has also been taken into account to improve detection. The residual AFAI is estimated based on surrounding Sargassum-free water. The AFAI background $\left(\mathrm{AFAI}_{\mathrm{bg}}\right.$ ) can be represented as a sum of three components (Equation (2)):

$$
\mathrm{AFAI}_{\mathrm{bg}}=\mathrm{AFAI}_{0}+\delta \mathrm{AFAI}_{\mathrm{w}}+\delta \mathrm{AFAI}_{\text {geom }}
$$

where $\mathrm{AFAI}_{0}$ retains the large-scale variation of AFAI (including potential residual atmospheric effects), $\delta \mathrm{AFAI}_{\mathrm{W}}$ is the deviation due to local characteristics of Sargassum-free ocean reflectance, and $\delta A F A I_{g e o m}$ is the deviation induced by the local variation of viewing geometry. 
Similarly, to Wang and Hu [10], the background AFAI that corresponds to Sargassumfree water was estimated here. A median filter in a $51 \times 51$ window was applied to the AFAI to estimate the AFAI background in the vicinity of each Sargassum pixel. The positive deviation of AFAI with respect to the background (סAFAI) was then computed to determine the presence of Sargassum.

The Level-1 TOA reflectance data measured by GOES-ABI were provided by the AERIS/ICARE Data and Services Center (www.icare.univ-lille.fr, Villeneuve d'Ascq Cedex, France, accessed on 7 April 2021). These data were used to compute NDVI because the GOES bands do not allow AFAI to be calculated. The extraction of the region of interest was operated for the study area shown in Figure 1, namely $13-17^{\circ} \mathrm{N}$ and $60-63^{\circ} \mathrm{W}$. The NIR data were over-sampled by a factor of 2 to reach a 500-m resolution using a bilinear method [26]. Then, a mask on the cloud and on the land was generated using a threshold value in the NIR band (NIR reflectance $>0.13$ ). Four successive acquisitions were averaged each hour to derive an hourly product. Such a method not only improves the SNR and the data quality but also decreases the amount of cloudy pixels. Indeed, because of the speed at which clouds travel, they change position within an hour. As the cloud masking procedure is applied before averaging, cloud-free observations are favored in the hourly product.

NDVI (Equation (3)) is computed for all the pixels of the hourly composite image. Such an index detects the increase of the vegetation reflectance located between $640 \mathrm{~nm}$ $\left(\lambda_{1}\right)$ and $860 \mathrm{~nm}\left(\lambda_{2}\right)$, including the red-edge region of the spectrum located between 700 and $750 \mathrm{~nm}$ :

$$
\begin{gathered}
\text { NDVI }=\frac{R\left(\lambda_{2}\right)-R\left(\lambda_{1}\right)}{R\left(\lambda_{2}\right)+R\left(\lambda_{1}\right)} \\
R(\lambda)=f * R_{s}(\lambda)+(1-f) * R_{w}(\lambda)
\end{gathered}
$$

where $\mathrm{f}$ is the Sargassum fractional coverage, $\mathrm{R}_{\mathrm{s}}$ the Sargassum reflectance, and $\mathrm{R}_{\mathrm{w}}$ the Sargassum-free water reflectance.

Similarly, to the AFAI calculation, the background NDVI (NDVI ${ }_{\mathrm{bg}}$ ) was also obtained by applying a median filter in a $51 \times 51$ window to the NDVI. The positive deviation of NDVI, noted $\delta N D V I$, is calculated by subtracting the background NDVI (NDVI ${ }_{\text {bg }}$ ) from NDVI (Equation (5)):

$$
\delta \mathrm{NDVI}=\mathrm{NDVI}-\mathrm{NDVI}_{\mathrm{bg}}
$$

Such a subtraction corrects the NDVI for potential residual sun glint contamination and atmospheric effects, assuming the atmosphere is homogenous over the considered scene.

Unlike AFAI and because of its definition in Equation (3), NDVI is non-linearly linked to Sargassum sub-pixel fractional coverage. NDVI is rapidly saturated by the presence of Sargassum, therefore, NDVI cannot be used as quantitative information to derive Sargassum fractional coverage. An interesting synergistic strategy could be to primarily detect and quantify the abundance of Sargassum using AFAI calculated from daily MODIS data, and secondarily use the NDVI derived from GOES data to monitor the Sargassum dynamics.

The flowchart of the overall methodology used to combine MODIS and GOES data is shown in Figure 3. 
MODIS level 1

1 image / day / instrument

Gaseous and

Rayleigh correction

MODIS AFAI

(bands 667, 748 and 869)

₹-

Background MODIS AFAI

(local median filter)

MODIS AFAI deviation
$\mathrm{ABI} / \mathrm{GOES}$ level 1

1 image / 15 min

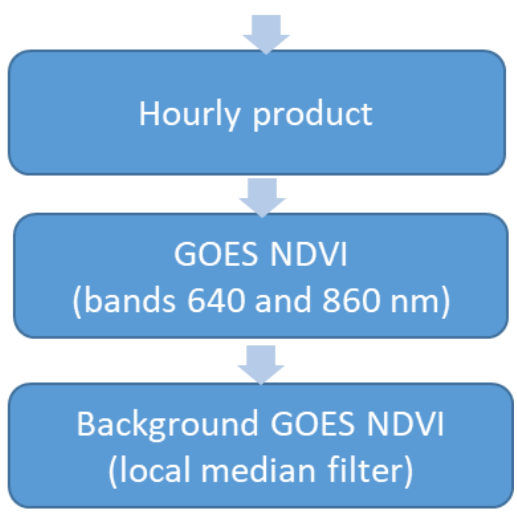

GOES NDVI deviation

\section{Hourly monitoring of Sargassum dynamics}

Figure 3. Flowchart of the overall methodology used to exploit the synergy between MODIS and GOES data for the characterization of Sargassum occurrence and dynamics.

\section{Results}

\subsection{AFAI Deviation from MODIS}

The $\delta$ AFAI product derived from the MODIS data on 8 August 2018 at 14:35 UTC allows a large area of Sargassum in the western part of Saint Lucia Island to be detected (Figure 4). Note that the grey areas correspond to clouds, glint, or land. The relationship proposed by [10] allows $\delta$ AFAI to be linked with the fraction of coverage " $\mathrm{f}$ " of Sargassum (Equation (6)).

$$
\delta \operatorname{AFAI}(\mathrm{f})=\mathrm{K} * \mathrm{f}
$$

where $\mathrm{K}=4.41 \times 10^{-2}$. A variation of $\delta$ AFAI from 0 to $10^{-3}$ means that the fraction of coverage varies between 0 and $2.3 \%$. Such low fractions of coverage can be estimated due to high MODIS radiometric sensitivity.

\subsection{NDVI Deviation from GOES Hourly Product}

$\delta$ NDVI calculated from GOES hourly product acquired on 8 August 2018 shows that the Sargassum aggregations detected with MODIS can be easily distinguished over the entire study area between 13:30 and 18:30 UTC, which corresponds to ca. 10:30-15:30 local solar time (Figure 5). Before 13:30 and after 18:30 UTC, the Sargassum aggregation cannot be detected because NDVI is significantly altered by the sensor noise, as a result of the weak amplitude of the upward oceanic radiation at high sun zenith angles. A movie illustrating the time variation of NDVI over the course of the day is provided as a Supplementary Materials of this paper.

Figures 4 and 5 show the significant potential benefit obtained from the synergy between sun-synchronous (MODIS) and geostationary sensors (GOES); MODIS is highly appropriate for the identification and the quantification of the Sargassum coverage while GOES is relevant to monitor the temporal dynamics of Sargassum. 


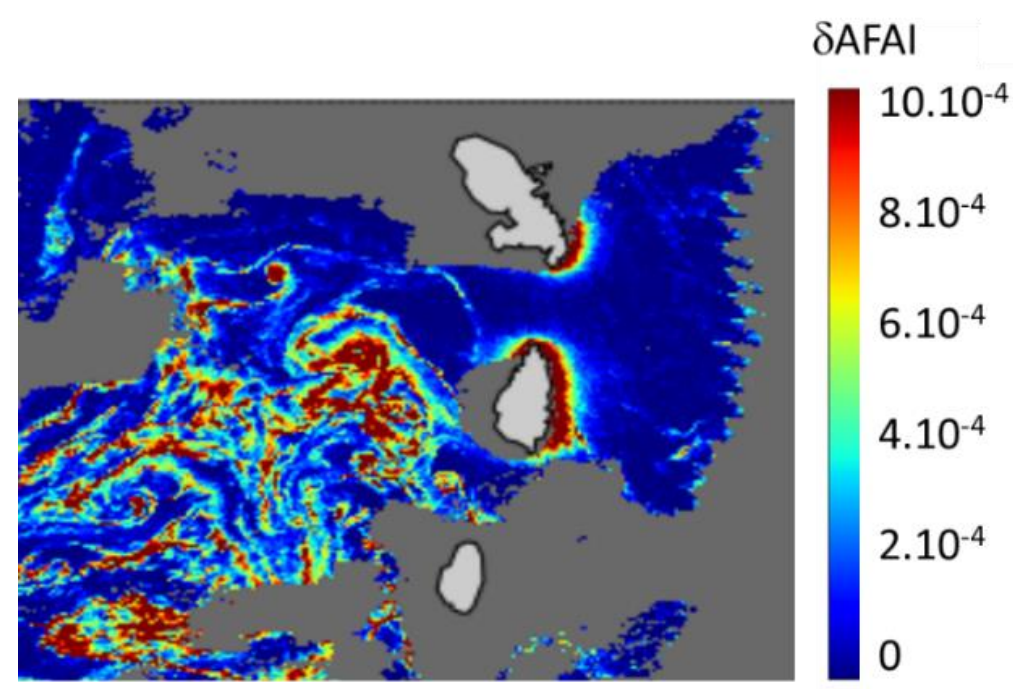

Figure 4. Alternative Floating Algae Index (AFAI) deviation ( $\mathrm{AAFAI}$ ) estimated from Terra-MODIS on 8 August 2018 at 14:35 UTC (ca. 10:30 local solar time).

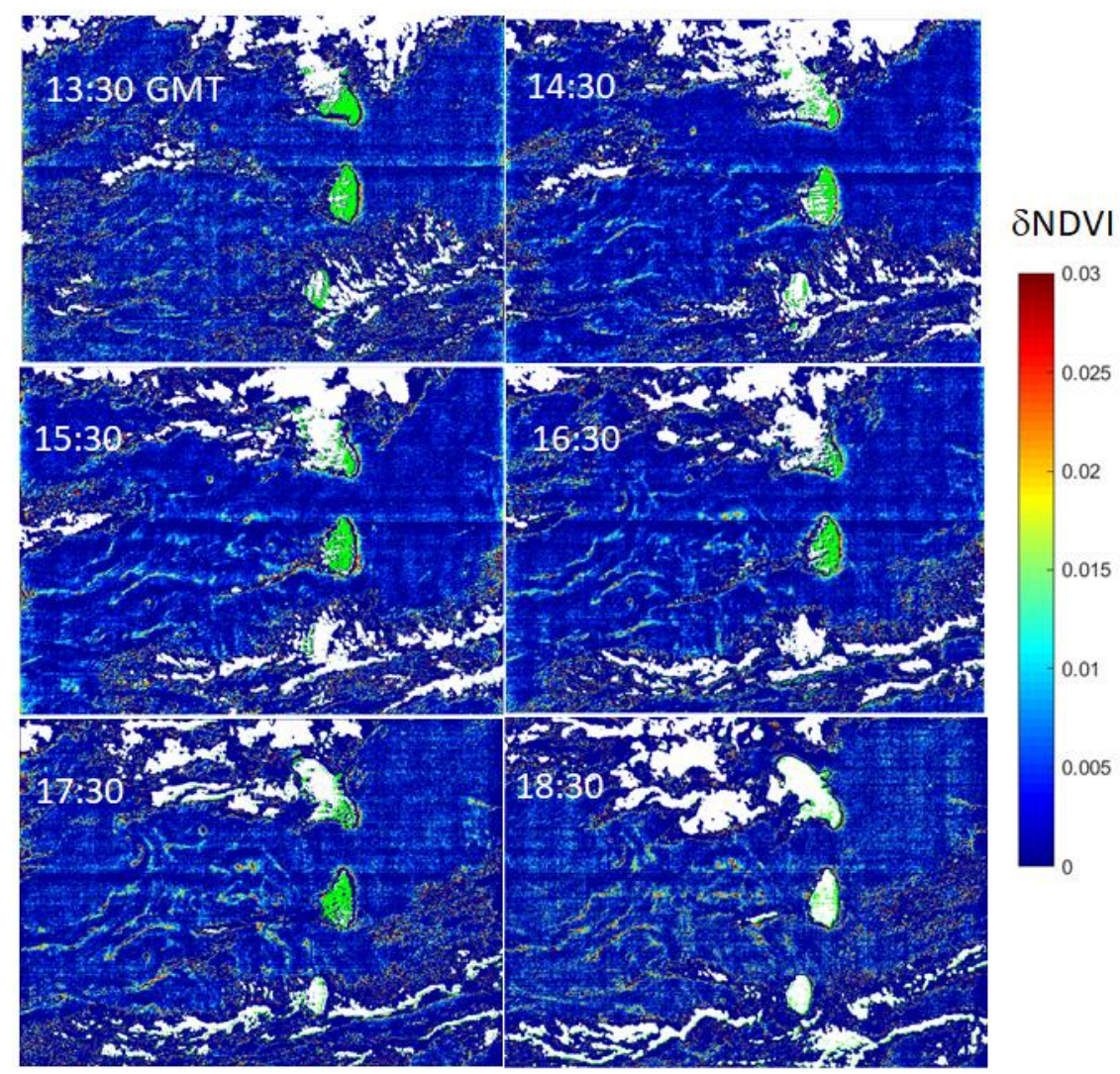

Figure 5. NDVI (Normalized Difference Vegetation Index) deviation ( $\delta$ NDVI) obtained from GOES hourly product on 8 August 2018 between 13:30 and 18:30 UTC (ca. 10:30 and 15:30 local solar time).

\subsection{GOES Noise Filtering}

Although NDVI applied to GOES data is a relevant index to monitor aggregations, its radiometric sensitivity is not necessarily well adapted for ocean targets, and will induce some noise in the data as observed in Figure 5 (North-South and West-East striping). The first approach that was adopted here to reduce the noise in the data was to use the high revisit rate of GOES data to calculate an hourly product instead of using the 15-min product.

In addition to hourly averaging, another approach to decrease (or remove) the noise is to use a more sophisticated filtering technique. Many filtering techniques have been 
developed to overcome noise effects. One of the most efficient techniques is the "non local means" filter method (hereinafter noted as NLM) developed by Buades et al. [27]. Local mean filtering, by nature, would have affected the very fine structure we would like to preserve. Unlike "local mean" filters, which take the mean value of a group of pixels surrounding a target pixel to smooth the data, the NLM filtering technique considers a mean of all pixels over the full area, which are weighted by the similarity of these pixels in terms of neighborhood average with the pixel of interest. Typically, a high similarity leads to a high weight value and vice-versa. Such a filtering method leads to a much greater post-filtering clarity, while maintaining a suitable level of details in the image as compared to "local mean" algorithms [28]. The application of the NLM method shows that the noise is significantly reduced over the whole scene (Figure 6). The NLM filtering allows the threshold value to be decreased to improve Sargassum aggregation detection.

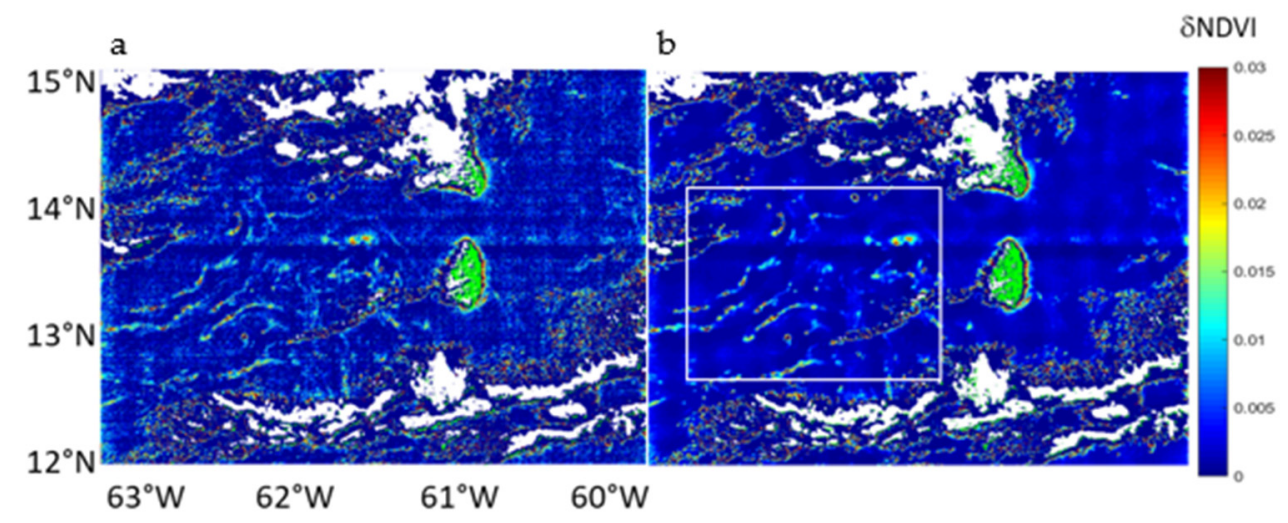

Figure 6. (a) NDVI deviation ( $\delta$ NDVI) calculated from GOES hourly data on 8 August 2018 at 16:30 UTC (left panel) and (b) application of the non-local means filtering technique (right panel). The white box indicates the location of the study area.

\section{4. $\delta$ NDVI Threshold Detection}

The application of both the hourly averaging and NLM filtering makes the water and the Sargassum modes more readily distinguishable. A threshold value can be used for $\delta$ NDVI to separate Sargassum from background. Sargassum aggregations are then identified and tracked from one hourly image to the next. The threshold value of $0.003 \delta$ NDVI was chosen by visualizing the histogram of the $\delta$ NDVI. For the case where Sargassum are not present, the histogram of $\delta$ NDVI consists only of one pronounced mode. In the case where Sargassum are present, the $\delta$ NDVI distribution shows a second mode overlapping the upper tail of the Sargassum-free ocean mode. The 0.003 threshold is optimally chosen to retain the non-ambiguous Sargassum optical signature (above 0.003 ) while rejecting most (99\%) of the Sargassum-free ocean (below 0.003).

\subsection{Performance of GOES Algorithm for Sargassum Identification}

The comparison of MODIS $\delta$ AFAI and GOES $\delta$ NDVI over the same area (white box in Figure 6b) and at the same time (8 August 2018, 16:30 UTC) shows that GOES can detect Sargassum corresponding to maximum $\delta$ AFAI above $8.10^{-4}$ (Figure $7 a$ ) i.e., a fractional coverage ca. $2 \%$ (Equation (6)). A so-called confusion matrix was computed to compare the Sargassum detection using GOES (i.e., $\delta$ NDVI > 0.003) with the Sargassum detection performed using MODIS $\left(\delta\right.$ AFAI $>1.79 \times 10^{-4}$ ) (Figure 7). Taking MODIS as the truth reference, the True Negative and True Positive rates of GOES detections are equal to $99 \%$ and $21 \%$ respectively and the False Positive and False Negative rates of GOES detections are equal to $1 \%$ and $79 \%$, respectively. These results show that the NDVI is reliable in detecting the highest fractional coverage of Sargassum. The 2D scatterplot (Figure 7c) shows a quasi-linear relationship between $\delta$ NDVI and $\delta \mathrm{AFAI}$, over the $\delta \mathrm{AFAI}>1.79 \times 10^{-4}$ range. This detection technique still satisfactorily retrieves the main patterns of Sargassum aggregations over the entire scene. This confirms the usefulness of GOES data to detect and 
track the largest Sargassum aggregations and study their dynamics. The $\delta$ NDVI detection is only validated by comparison with the $\delta \mathrm{AFAI}$ product. In the current study, in situ measurements were not available, however in this area, the presence of Sargassum was confirmed by numerous beaching reports (http:/ / sargassummonitoring.com/, accessed on 5 April 2021).
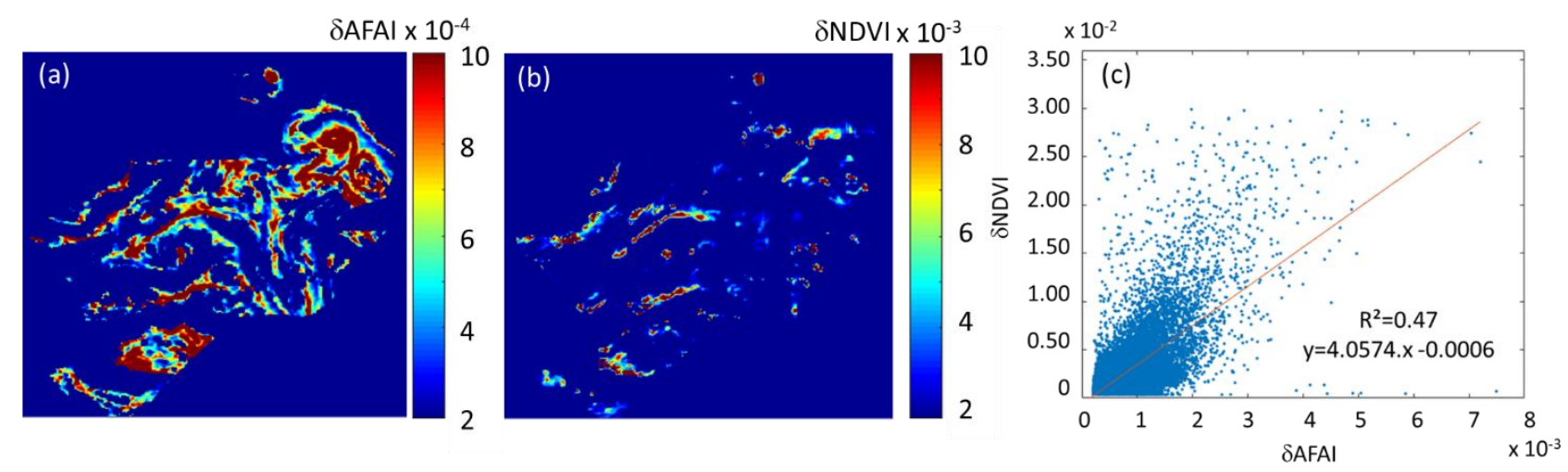

Figure 7. (a) Sargassum identification using MODIS ( $\left.\delta \mathrm{AFAI}>1.7910^{-4}\right),(\mathbf{b}) \mathrm{GOES}(\delta \mathrm{NDVI}>0.003)$, and (c) the 2D scatterplot $\delta \mathrm{NDVI}=\mathrm{f}(\delta \mathrm{AFAI})$, over the $\delta \mathrm{AFAI}>1.79 \times 10^{-4}$ range

\section{Discussion}

\subsection{Impact of the Hourly GOES Product on the Noise Filtering and on the SNDVI Value}

The first approach adopted here was to compute an hourly product instead of using the 15-min product. The higher the sun zenith angle, the weaker the SNR. Such a technique decreases the level of noise in the data. When a given number of $n$ measurement values are averaged, the noise decreases by $\sqrt{n}$ and then the SNR is multiplied by $\sqrt{n}$. Here, because four images are averaged, the SNR is then multiplied by 2 (provided that the given pixel is cloud free for the four images). It also decreases the overall cloud cover within the area. However, this noise filtering approach has an impact on the Sargassum aggregation detection area. Since the drift velocity was estimated at $1 \mathrm{~m} \cdot \mathrm{s}^{-1}$ from GOES data, the drift distance over the course of one hour is about $3600 \mathrm{~m}$, which corresponds to 7.2 pixels at a 500-m resolution. Thus, some pixels containing Sargassum and located on the aggregation edges may be averaged with Sargassum-free pixels. However, as GOES is used to estimate the velocity and direction of Sargassum aggregations, not to quantify their abundance, there is no downside to use such hourly averaged data.

\subsection{Sargassum Aggregation Tracking}

The high temporal resolution of GOES sensor is well adapted to track individual Sargassum aggregations, and then to investigate their drift speed and direction.

Hourly GOES Sargassum detections of 8 August 2018 were superimposed on the same plot in Figure 8. Each detection is represented with several dots scattered across the extent of the corresponding pixel. The number of dots is proportional to the $\delta$ NDVI value ( 0 for $\delta \mathrm{NDVI} \leq 0.003$ to 15 for $\delta \mathrm{NDVI} \geq 0.01$ ), i.e., the dot density in a pixel corresponds to the Sargassum abundance. The color of the dots corresponds to the observation time, such that detections retrieved at different observation times in the same pixel can be distinguished. The aggregations retrieved at a given acquisition time are revealed by dot patterns of the same color and tracked in the figure. 


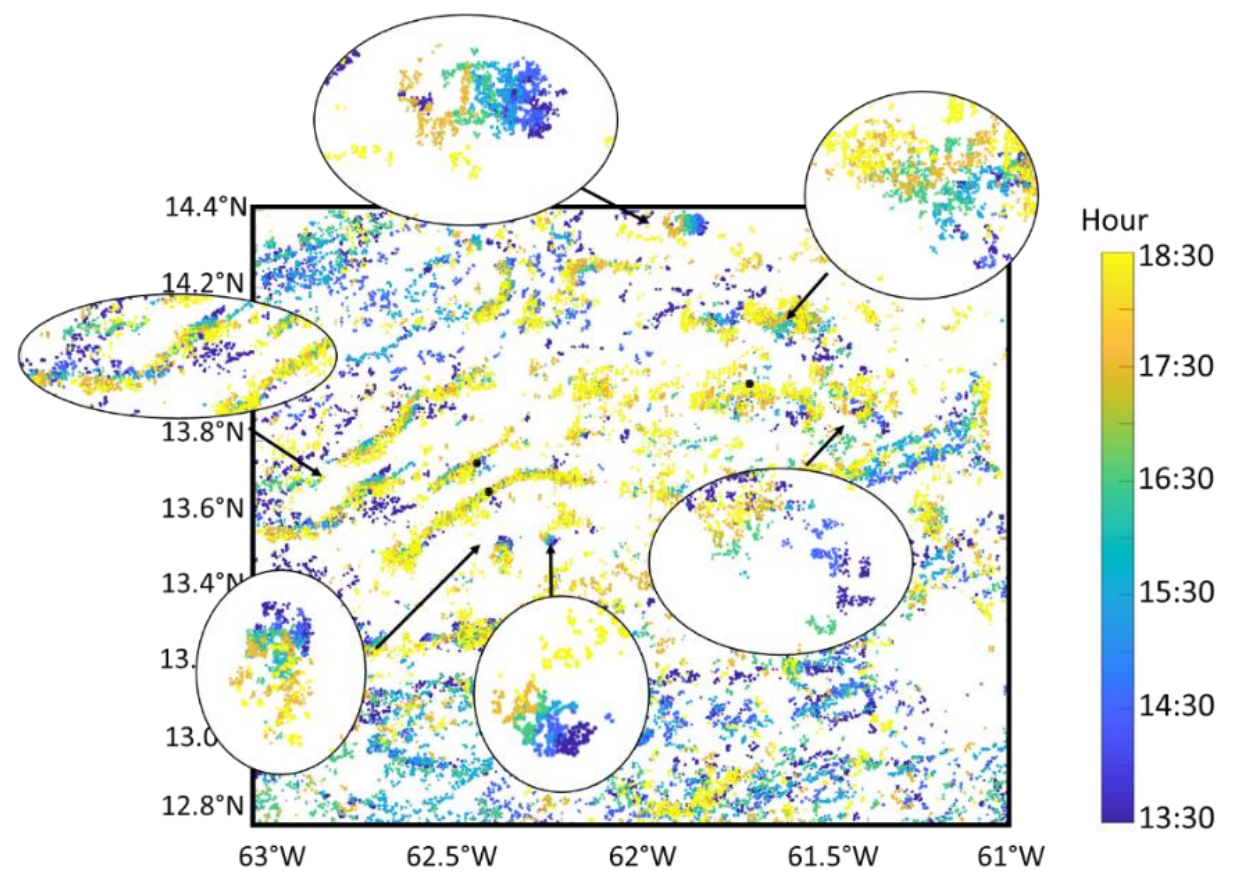

Figure 8. Superimposition of hourly GOES Sargassum identification ( $\delta$ NDVI > 0.003) over the course of 8 August 2018 to enhance the visualization of the Sargassum aggregation motion. The dot color indicates the time of observation. Some examples of Sargassum motion are enlarged.

Persistent and rather compact aggregations were first tracked. Their start position (13:30, blue) and end position (18:30, yellow) was determined visually for each selected aggregation. Then, the direction and speed value of about 20 aggregations were estimated with an accuracy that depends on the size of each aggregation. Accuracy was lower than or equal to $2 \mathrm{~km}$ in $5 \mathrm{~h}$, which corresponds to about $0.1 \mathrm{~m} \cdot \mathrm{s}^{-1}$. Although the method is manual, the main circulation pattern retrieved with that method, as illustrated by Figure 9 .

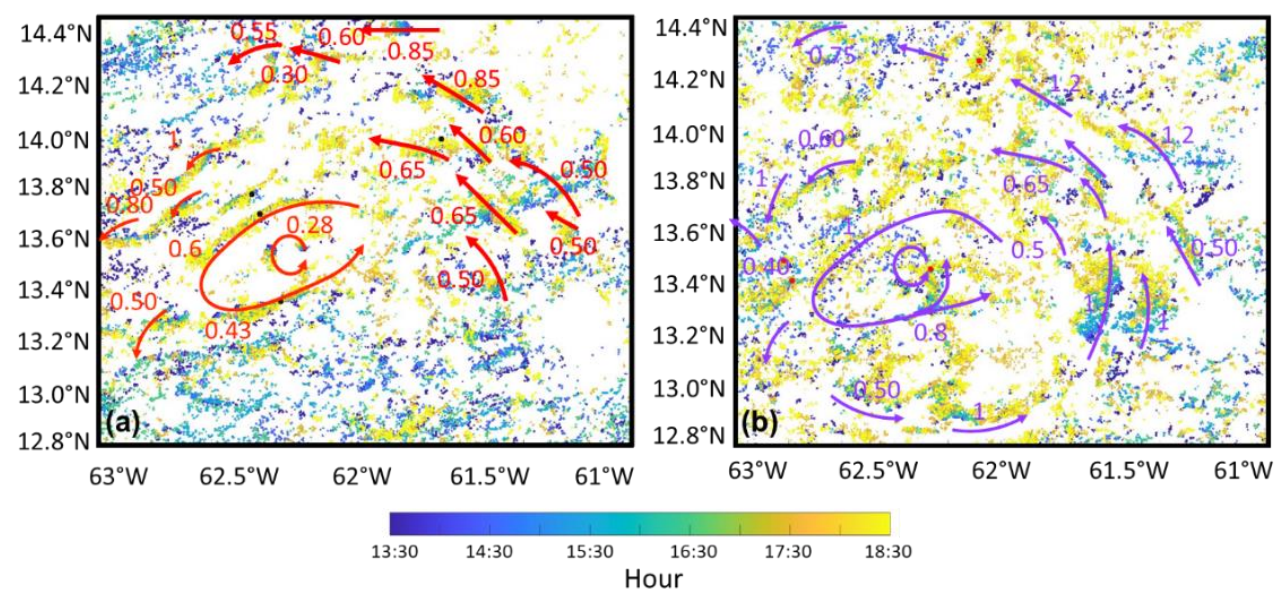

Figure 9. Sargassum aggregations motion (speed and direction) calculated from GOES hourly data over the course of $5 \mathrm{~h}$; the arrows highlight the occurrence of an eddy (in the west part of the image at $62.2^{\circ} \mathrm{W}$ ) and a northwestward drift (in the east part of the image at $61.5^{\circ} \mathrm{W}$ ): (a) On 8 August 2018 (red arrows) and (b) on 9 August 2018 (purple arrows).

The purple and red arrows show the direction and speed of the Sargassum aggregations as estimated from the GOES time series over the course of $5 \mathrm{~h}$. The retrieved motion shows two main features. First, aggregations are subjected to one cyclonic eddy centered at $62.2^{\circ} \mathrm{N}-3.6^{\circ} \mathrm{W}$ (Figure 9a). Second, other aggregations move northwestwards (Figure 9a). The day after (9 August 2018, Figure 9b), aggregations remain organized along an eddy 
on the western part, thus confirming the real occurrence of the eddy observed the day before. This aggregation appears to shift about $8.5 \mathrm{~km}$ to the southwest during one day, corresponding to a velocity of $0.1 \mathrm{~m} \cdot \mathrm{s}^{-1}$. The eddy seems to strengthen with the diameter increasing by $75 \%$ to approximately $120 \mathrm{~km}$. In the meantime, in the eastern part, the velocity of northwestward current also increased in magnitude (arrows).

Our analysis also points out the feasibility of tracking aggregations from one day to another by estimating the Sargassum drift distance. Table 1 provides the drift distance and velocity for four different Sargassum aggregations that were identified on 8 and 9 August 2018 at 16:30 UTC (Figure 10). Although a significant drift (white arrows) is observed, it remains possible to locate the aggregation.

Table 1. Estimation of drift for the four Sargassum aggregations indicated in Figure 10.

\begin{tabular}{|c|c|c|c|c|c|}
\hline & \multicolumn{2}{|c|}{$\begin{array}{c}\text { Drift Velocity } \\
\mathrm{m} \cdot \mathbf{s}^{-1}\end{array}$} & \multirow{2}{*}{$\begin{array}{c}\text { Drift Distance } \\
t=19 \mathrm{~h} \text { (from 18:30 on } 8 \\
\text { August to 13:30 on } 9 \text { August) }\end{array}$} & \multirow{2}{*}{$\begin{array}{c}\text { Drift Velocity } \\
\mathrm{m} \cdot \mathrm{s}^{-1}\end{array}$} & \multirow[b]{2}{*}{ Direction } \\
\hline & $\begin{array}{c}8 \text { August- } \\
t=5 \mathrm{~h}\end{array}$ & $\begin{array}{c}9 \text { August- } \\
t=5 \mathrm{~h}\end{array}$ & & & \\
\hline Aggregation 1 (R1) & 0.4 & 0.8 & $41 \mathrm{~km}$ & 0.6 & along the eddy \\
\hline Aggregation 2 (R2) & 0.6 & 1 & $55 \mathrm{~km}$ & 0.80 & along the eddy \\
\hline Aggregation 3 (R3) & 0.5 & 1 & $51 \mathrm{~km}$ & 0.75 & along the eddy \\
\hline Aggregation 4 (R4) & 0.5 & 1.2 & $58 \mathrm{~km}$ & 0.85 & northwestward \\
\hline
\end{tabular}

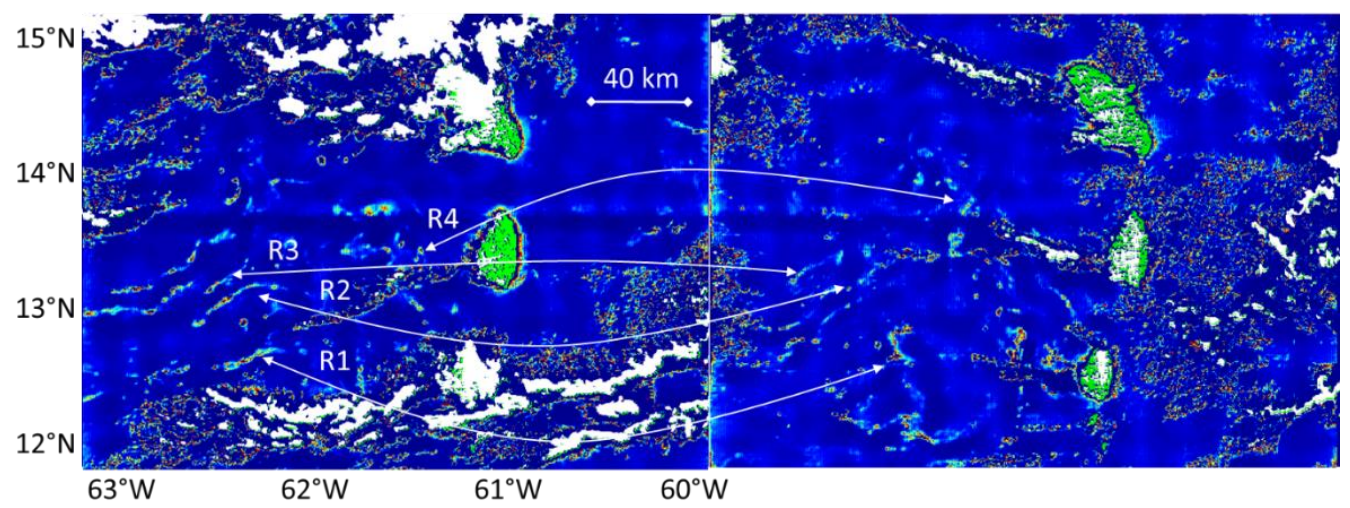

Figure 10. Comparison between the NDVI deviation (סNDVI) (i.e., Sargassum optical signature) measured from GOES data on 8 August 2018 at 16:30 UTC (left panel) with a similar observation made $24 \mathrm{~h}$ after, on 9 August 2018 at 16:30 UTC (right panel). The white arrows link four identified aggregations from one day to the other.

Monitoring aggregations from one day to the next is possible by visual analysis. Such an analysis can help to improve forecasting of the short-term drift, hence the stranding location and time.

\subsection{Consistency of Observed Drift with Satellite Derived Current and Temperature Data}

Despite its coarse temporal (5 days) and spatial (about $40 \mathrm{~km}$ ) resolutions, the OSCAR product reveals the occurrence of an eddy (Figure 11) near the eddy that was identified using GOES observations (Figure 9a). A northwestward jet also appears in the western area (Figure 11a). The oceanic circulation observed in Figure 9 is then in agreement with the OSCAR-current speed data (Figure 11). Finally, it is interesting to note that a temperature anomaly can be observed by GHRSST data (Figure $11 \mathrm{~b}, \mathrm{c})$ in the specific area $\left(3.5^{\circ} \mathrm{N}, 62.4^{\circ} \mathrm{W}\right.$ ) on 8 and 9 August 2018, which is consistent with the occurrence of an eddy there. 

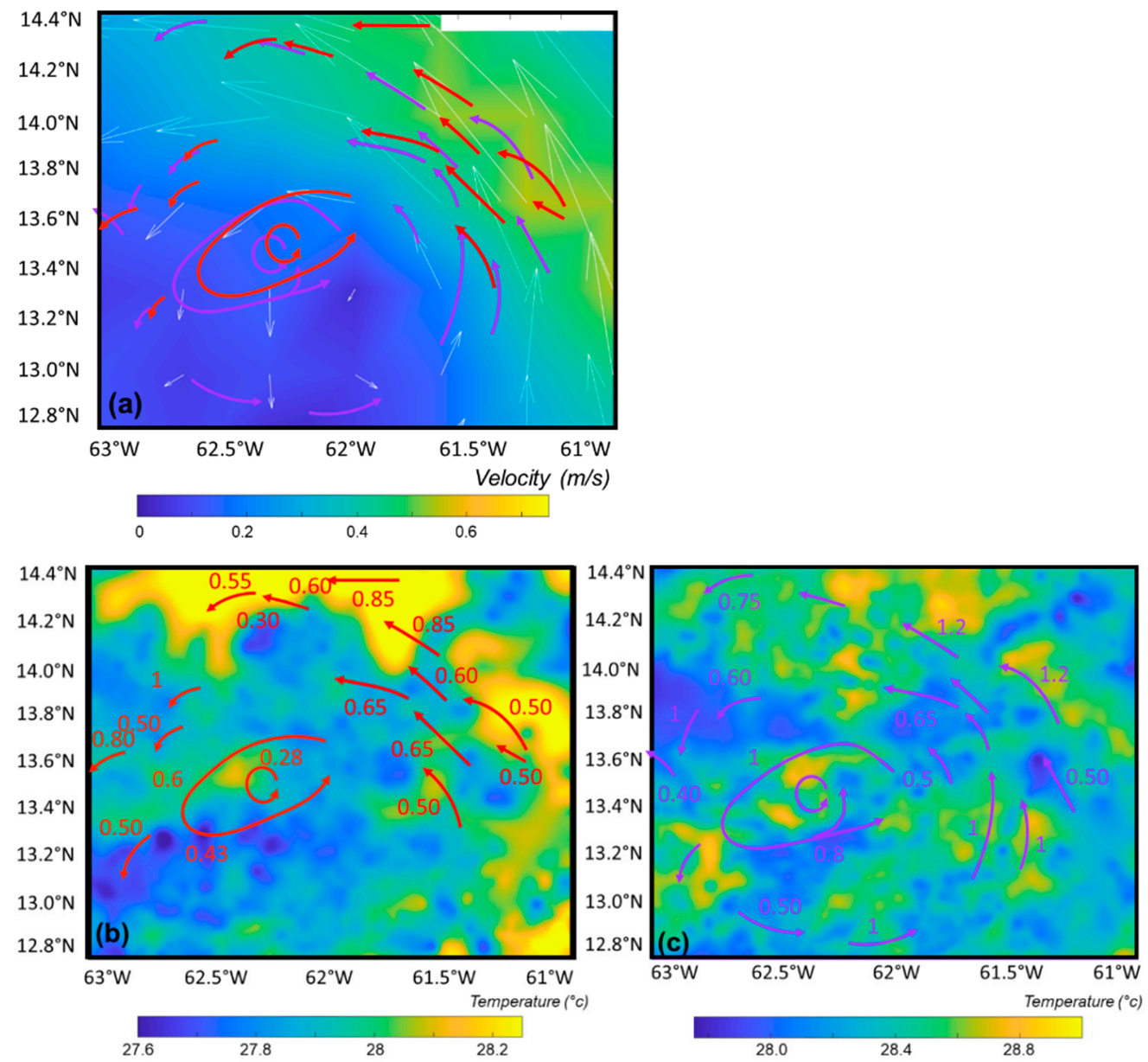

Figure 11. (a) Modeled Oscar Third Degree Sea Surface Velocity, (b) GHRSST (Group for High Resolution Sea Surface Temperature) of the water mass on 8 August 2018, and (c) GHRSST temperature of the water mass on 9 August 2018.

\subsection{Pertinence of GOES Sargassum Product for Transport Models}

Systematic comparison of observed Sargassum drift with the components acting on the drift (current, wind, and waves) will help to improve drift modeling and the subsequent drift forecast for a short-term period, and thus the stranding in location and time. There are several unknowns in the drift parameters, such as wind effect and Stokes contribution. Comparison of observed drift with the different components can help to better constrain these parameters.

Here, the comparison of the observed drift with modeled aggregations drift (Figure 12) reveals some differences. The eddy observed with GOES is absent in the modeled aggregations drift velocity. The modeled advection jet towards the northwest direction is consistent with the Sargassum aggregations motion observation, but with a southwestward shift of hydrodynamics structures. The inflexion of the current direction is encountered further west in the model velocity drift. In addition, the modeled drift velocity is underestimated in comparison to GOES observed velocity; typically, the velocity ranges from 0.3 to $0.4 \mathrm{~m} \cdot \mathrm{s}^{-1}\left(61.4^{\circ} \mathrm{N}-4^{\circ} \mathrm{W}\right)$ for the model vs. 0.6 to $0.85 \mathrm{~m} \cdot \mathrm{s}^{-1}$ for GOES observations. Finally, even if these differences are small, their impact will grow when simulating the Sargassum transport. Consequently, these differences have to be reduced as much as possible, or at least, estimated. 


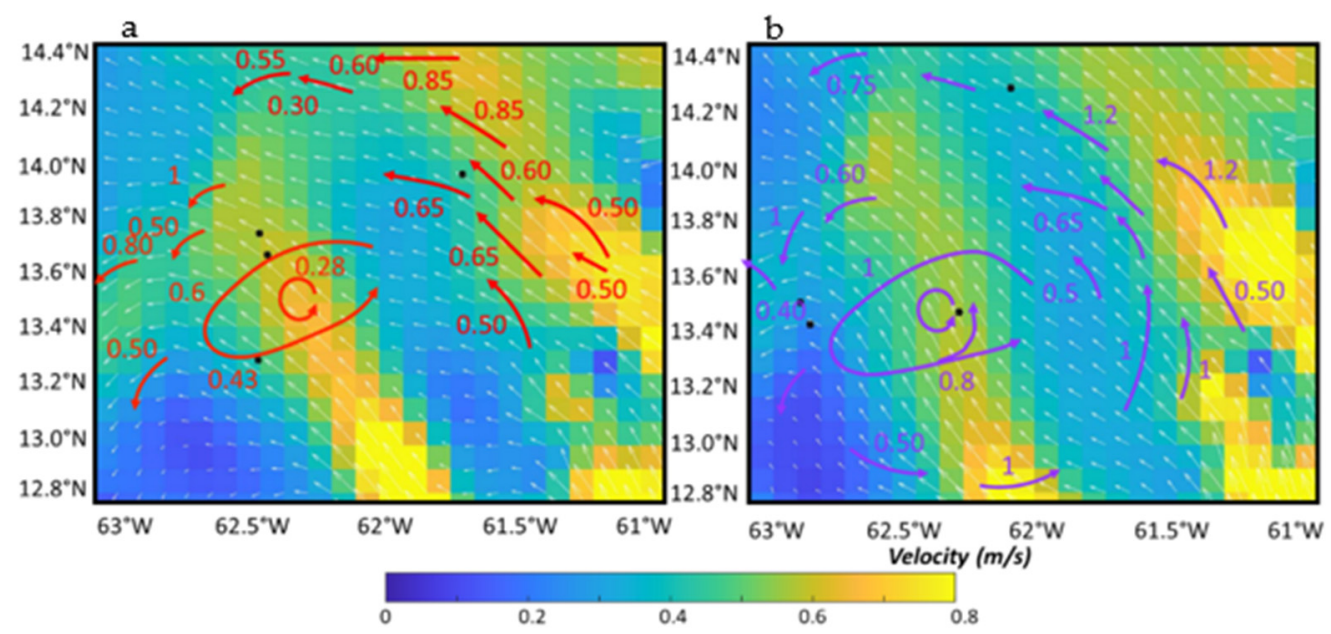

Figure 12. Modeled surface velocity (combining large scale current velocity, wind velocity, Stokes velocity): (a) On 8 August 2018 and (b) on 9 August 2018; speed and direction are shown using color scale and white arrows respectively. The drift of aggregations derived from GOES data (red and purple arrows for 8 and 9 August, respectively) was superimposed to ease the comparison between observed and modeled motion.

One way of improving transport model is to evaluate the wind effect in the modeling drift. The effect of wind was determined from large scale analysis $[18,23]$ and non-local analysis. Moreover, here the wind is estimated from a large-scale model [18,23], which may not be accurate in the region. Finally, Stokes velocity has to be taken into account when modeling Sargassum drift. However, due to their density, Sargassum aggregations may dampen high frequency waves. Large-scale models of Stokes drift do not take into account this effect and thus the Stokes velocity contribution may be reduced by Sargassum. Therefore, wind and the Stokes effect on Sargassum drift are poorly known and these images may help to better investigate these effects.

\section{Conclusions}

In this paper, the synergy between a sun-synchronous (MODIS) and a geostationary (GOES) sensor for studying the spatio-temporal variation of Sargassum in the North Atlantic was investigated. Well-defined radiometric indices based on the reflectance at specific wavelengths were used for each sensor to derive Sargassum occurrence and abundance. While MODIS AFAI could be linked to the Sargassum fractional coverage and to the biomass, it suffered from heavy cloud masking and low revisit frequency. Current geostationary satellite such as GOES-16, with an hourly revisit, are well suited to identify and monitor Sargassum aggregations but with a weaker sensitivity. A "non local mean" filtering method was satisfactorily used to further reduce noise level. NDVI and AFAI were compared for the same acquisition time and showed a satisfactory agreement. Geostationary data allow individual Sargassum aggregations to be tracked over the course of several hours per day. The data were shown to be highly relevant for deriving their transport speed and direction. It was shown that Sargassum could drift between 40 and $60 \mathrm{~km}$ over the course of $19 \mathrm{~h}$. The comparison of the remotely sensed drift with the drift velocity modeled from a global ocean circulation model showed a significant discrepancy. A systematic comparison of observed and simulated drift will help to better constrain drift components. This study demonstrated that the use of geostationary data for Sargassum detection and tracking is a promising approach to improve Sargassum drift modeling and forecast of Sargassum transport and stranding. The Sargassum detections from GOES and MODIS for the same acquisition time were compared. While GOES only retrieves $21 \%$ of the MODIS detections, the main Sargassum aggregations with high $\delta$ AFAI values were retrieved with a satisfactory agreement. The forecast of Sargassum transport is of primary importance to 
support the need of stakeholders and end-users that make decisions in link with socioeconomic interests for the Antilles Islands.

Supplementary Materials: The following are available online at https:/ / www.mdpi.com/article/10 $.3390 / \mathrm{rs} 13081444 / \mathrm{s} 1$, Video S1: GOES SNDVI animation from 13:30 to 18:30 on 8 August 2018 with hourly product (Section 3) and NLM filtering (Section 4.1).

Author Contributions: Conceptualization, A.M.; Data curation, C.C., J.D. and P.B.; Formal analysis, C.C., J.D., L.B. and M.C.; Funding acquisition, L.B.; Methodology, A.M., J.D., L.B. and M.C.; Software, A.M. and J.D.; Validation, C.C.; Writing-original draft, A.M.; Writing-review \& editing, C.C., J.D., L.B. and M.C. All authors have read and agreed to the published version of the manuscript.

Funding: This research was funded by the French program of the ministry of research "Investissement d'Avenir" run by the National Research Agency (FORESEA project, grant ANR-19-SARG-0007). MODIS AFAI data were produced in the frame of SAREDA_DA project, funded by TOSCA-CNES and IRD.

Acknowledgments: The authors would like to thank the NASA, NOAA, and AERIS/ICARE for the GOES and MODIS data; MERCATOR for the drift data.

Conflicts of Interest: The authors declare no conflict of interest.

\section{References}

1. Gower, J.; Hu, C.; Borstad, G.; King, S. Ocean Color Satellites Show Extensive Lines of Floating Sargassum in the Gulf of Mexico. IEEE Trans. Geosci. Remote. Sens. 2006, 44, 3619-3625. [CrossRef]

2. Gower, J.; King, S.; Goncalves, P. Global monitoring of plankton blooms using MERIS MCI. Int. J. Remote. Sens. 2008, 29 , 6209-6216. [CrossRef]

3. Gower, J.F.; King, S.A. Distribution of floating Sargassum in the Gulf of Mexico and the Atlantic Ocean mapped using MERIS. Int. J. Remote Sens. 2011, 32, 1917-1929. [CrossRef]

4. Gower, J.; Young, E.; King, S. Satellite images suggest a new Sargassum source region in 2011. Remote Sens. Lett. 2013, 4, 764-773. [CrossRef]

5. Gower, J.; King, S. The distribution of pelagic Sargassum observed with OLCI. Int. J. Remote Sens. 2019, 41, 1-11. [CrossRef]

6. $\mathrm{Hu}, \mathrm{C}$. A novel ocean color index to detect floating algae in the global oceans. Remote. Sens. Environ. 2009, 113, 2118-2129. [CrossRef]

7. He, M.X.; Liu, J.; Yu, F.; Li, D.; Hu, C. Monitoring green tides in Chinese marginal seas. In Handbook of Satellite Remote Sensing Image Interpretation: Applications for Marine Living Resources Conservation and Management; Morales, J., Stuart, V., Platt, T., Sathyendranath, S., Eds.; EU PRESPO and IOCCG: Dartmouth, NS, Canada, 2011; pp. 111-124.

8. Hu, C.; Li, D.; Chen, C.; Ge, J.; Muller-Karger, F.E.; Liu, J.; Yu, F.; He, M.X. On the recurrent Ulva prolifera blooms in the Yellow Sea and East China Sea. J. Geophys. Res. Ocean. 2010, 115. [CrossRef]

9. Hu, C.; Feng, L.; Hardy, R.F.; Hochberg, E.J. Spectral and spatial requirements of remote measurements of pelagic Sargassum macroalgae. Remote. Sens. Environ. 2015, 167, 229-246. [CrossRef]

10. Wang, M.; Hu, C. Mapping and quantifying Sargassum distribution and coverage in the Central West Atlantic using MODIS observations. Remote Sens. Environ. 2016, 183, 350-367. [CrossRef]

11. Ody, A.; Thibaut, T.; Berline, L.; Changeux, T.; André, J.-M.; Chevalier, C.; Blanfuné, A.; Blanchot, J.; Ruitton, S.; Stiger-Pouvreau, V.; et al. From In Situ to satellite observations of pelagic Sargassum distribution and aggregation in the Tropical North Atlantic Ocean. PLoS ONE 2019, 14, e0222584. [CrossRef]

12. Wang, M.; Hu, C.; Cannizzaro, J.; English, D.; Han, X.; Naar, D.; Lapointe, B.; Brewton, R.; Hernandez, F. Remote Sensing of Sargassum Biomass, Nutrients, and Pigments. Geophys. Res. Lett. 2018, 45, 12-359. [CrossRef]

13. Kwon, K.; Choi, B.-J.; Kim, K.Y.; Kim, K. Tracing the trajectory of pelagic Sargassum using satellite monitoring and Lagrangian transport simulations in the East China Sea and Yellow Sea. ALGAE 2019, 34, 315-326. [CrossRef]

14. Rouse, J.W.; Haas, R.H.; Schell, J.A.; Deering, D.W. Monitoring vegetation systems in the Great Plains with ERTS. NASA Spec. Publ. 1974, 351, 309.

15. Tucker, C.J. Red and photographic infrared linear combinations for monitoring vegetation. Remote. Sens. Environ. 1979, 8, 127-150. [CrossRef]

16. van Tussenbroek, B.I.; Arana, H.A.; Rodríguez-Martínez, R.E.; Espinoza-Avalos, J.; Canizales-Flores, H.M.; González-Godoy, C.E.; Barba-Santos, M.G.; Vega-Zepeda, A.; Collado-Vides, L. Severe impacts of brown tides caused by Sargassum spp. on near-shore Caribbean seagrass communities. Mar. Pollut. Bull. 2017, 122, 272-281. [CrossRef]

17. Resiere, D.; Mehdaoui, H.; Florentin, J.; Gueye, P.; Lebrun, T.; Blateau, A.; Viguier, J.; Valentino, R.; Brouste, Y.; Kallel, H.; et al. Sargassum seaweed health menace in the Caribbean: Clinical characteristics of a population exposed to hydrogen sulfide during the 2018 massive stranding. Clin. Toxicol. 2021, 59, 215-223. [CrossRef] [PubMed] 
18. Berline, L.; Ody, A.; Jouanno, J.; Chevalier, C.; André, J.-M.; Thibaut, T.; Ménard, F. Hindcasting the 2017 dispersal of Sargassum algae in the Tropical North Atlantic. Mar. Pollut. Bull. 2020, 158, 111431. [CrossRef] [PubMed]

19. Savtchenko, A. Terra and Aqua MODIS products available from NASA GES DAAC. Adv. Space Res. 2004, 34, 710-714. [CrossRef]

20. Kalluri, S.; Alcala, C.; Carr, J.; Griffith, P.; Lebair, W.; Lindsey, D.; Race, R.; Wu, X.; Zierk, S. From Photons to Pixels: Processing Data from the Advanced Baseline Imager. Remote. Sens. 2018, 10, 177. [CrossRef]

21. Aminou, D.M.A.; Ottenbacher, A.; Hanson, C.G.; Pili, P.; Müller, J.; Blancke, B.; Jacquet, B.; Bianchi, S.; Coste, P.; Pasternak, F.; et al. Meteosat Second Generation: The MSG-1 imaging radiometer performance results at the end of the commissioning phase. In Proceedings of the Earth Observing Systems VIII; Optical Science and Technology, SPIE's 48th Annual Meeting, San Diego, CA, USA, 10 November 2003; Volume 5151, pp. 599-608.

22. Bonjean, F.; Lagerloef, G.S. Diagnostic model and analysis of the surface currents in the tropical Pacific Ocean. J. Phys. Oceanogr. 2002, 32, 2938-2954. [CrossRef]

23. Jouanno, J.; Benshila, R.; Berline, L.; Soulié, A.; Radenac, M.H.; Morvan, G.; Diaz, F.; Sheinbaum, J.; Chevalier, C.; Thibaut, T.; et al. A NEMO-based model of Sargassum distribution in the Tropical Atlantic: Description of the model and sensitivity analysis (NEMO-Sarg1. 0). Geosci. Model Dev. Discuss 2020, 1-30. [CrossRef]

24. Von Schuckmann, K.; Le Traon, P.-Y.; Alvarez-Fanjul, E.; Axell, L.; Balmaseda, M.; Breivik, L.-A.; Brewin, R.J.W.; Bricaud, C.; Drevillon, M.; Drillet, Y.; et al. The Copernicus Marine Environment Monitoring Service Ocean State Report. J. Oper. Oceanogr. 2016, 9, s235-s320. [CrossRef]

25. Siegel, D.A.; Wang, M.; Maritorena, S.; Robinson, W. Atmospheric correction of satellite ocean color imagery: The black pixel assumption. Appl. Opt. 2000, 39, 3582-3591. [CrossRef]

26. Parker, J.A.; Kenyon, R.V.; Troxel, D.E. Comparison of Interpolating Methods for Image Resampling. IEEE Trans. Med Imaging 1983, 2, 31-39. [CrossRef]

27. Buades, A.; Coll, B.; Morel, J.-M. A review of image denoising algorithms, with a new one. SIAM Multiscale Modeling Simul. 2005, 4, 490-530. [CrossRef]

28. Buades, A.; Coll, B. Non-local means denoising. Image Process. Line 2011, 1, 208-212. [CrossRef] 